HEARES 01682

\title{
Cochlear blood flow in response to dilating agents
}

\author{
K. Agnetha Ohlsén, Anne Didier, David Baldwin, Josef M. Miller, Alfred L. Nuttall \\ and Elisabeth Hultcrantz
}

Kresge Hearing Research Institute, The University of Michigan, Ann Arbor, MI 48109-0506, USA

(Received 12 April 1991; accepted 10 September 1991)

\begin{abstract}
Reduced cochlear blood flow (CBF) has been implicated in various pathologies of the inner ear, including sudden deafness, noise-induced hearing loss and Meniere's diseasc. Thus the aim of some current therapeutic regimens to treat these conditions is to increase CBF and thereby improve oxygenation of the inner ear tissues. Most of the vasodilating agents in clinical use, however, do not have specific experimental evidence to support their effects on CBF. The hypotension which can follow systemic administration may limit their local effectiveness and general utility, just as it complicates the interpretation of the data in animal experiments. In the current study we investigated the effect of six agents, known for their systemic cardiovascular actions, on CBF: hydralazine, sodium nitroprusside, papaverine, nicotinic acid, verapamil and histamine. The effect of these drugs was studied after topical applications on the round window membrane (RWM) and systemic intravenous administrations. CBF was monitored with a laser Doppler flowmeter (LDF). Topical administration of sodium nitroprusside was the most effective in increasing CBF, followed, in order, by hydralazine and histamine. No change in CBF was observed for papaverine, verapamil or nicotinic acid. Systemic administrations of all the agents caused a marked decrease in blood pressure and variable effects on CBF. We discuss the CBF changes in relation to the different pharmacological mechanisms of action of each drug. The study demonstrates the effectiveness of topical application of vasodilating agents in increasing $\mathrm{CBF}$.
\end{abstract}

Guinea pig; Hydralazine; Sodium nitroprusside; Nicotinic acid; Papaverine; Verapamil; Histamine

\section{Introduction}

Microcirculation piays an essential role in maintaining inner ear homeostasis. The cochlea's very intricate and extensive vascular system (Axelsson, 1971) supports a tight coupling between cochlear function and oxygenation of the cochlear fluids (Lawrence et al., 1975; Brown et al., 1983). Moreover, it has been suggested that the vascular pathology of reduced inner ear blood flow may contribute to sudden deafness (Zajtchuk, 1979; Johnson et al., 1984), Meniere's disease (Prazma, 1981), presbyacusis (Axelsson, 1971; Johnsson and Hawkins, 1972), hearing loss associated with hypercholesterolemia (Cummingham and Goetzinger, 1974; Tami, 1985) and noise-induced hearing loss (Thorne and Nuttall, 1987). Treatments in use today are partly based on this assumption and attempt to increase the cochlear blood flow (Mattox, 1980; Hultcrantz, 1988; Nakatsu and Diamond, 1989). For the most part, experimental evidence supporting the effectiveness of these treatments for increasing CBF is lacking. Furthermore, the use of many drug treatments is complicated by cardiovascular side effects, such as

Correspondence to: Alfred L. Nuttall, Ph.D., The University of Michigan, Kresge Hearing Research Institute, 1301 E. Ann St., Ann Arbor, MI 48109-0506, USA. decreased blood pressure in response to systemically applied vasodilating drugs.

The purpose of the current investigation was to examine the effects on the CBF of six agents which are known for their vasodilating effects. The pharmacological pathway of action of these drugs in producing vasodilation varies, and they were selected to examine the availability of each pathway in the control of CBF. This study evaluated their influence on CBF when administered both by intravenous (IV) injections and by topical application on the round window membrane (RWM). The comparison of the two routes of administration allows the assessment of the specific action of each drug in the cochlea, independent of its systemic effects. The dosages of the drugs were extrapolated from the human therapeutic range. Laser Doppler flowmetry (LDF) was used for measuring tiic CBF. LDF has been shown to provide quantitative information about the dynamic changes of CBF (Miller et al., 1983; Miller et al., 1984; Sillman et al., 1988; Miller and Dengerink, 1988).

\section{Methods}

\section{Animals and preparation}

Ninety-five pigmented guinea pigs of either sex, weighing 240-500 $\mathrm{g}$ were used in these studies. All 
subjects had a normal Preyer's reflex and were free of middle ear infection as assessed directly under the microscope. Anesthesia was induced by Nembutal (15 $\mathrm{mg} / \mathrm{kg}$, IP initially, followed by $7.5 \mathrm{mg} / \mathrm{kg}$ every two hours) and Innovar-Vet $(0.4 \mathrm{ml} / \mathrm{kg}$, IM initially, followed by $0.2 \mathrm{ml} / \mathrm{kg}$ every hour). Core body temperature, measured with a rectal probe, was maintained at $38 \pm 1^{\circ} \mathrm{C}$ with a thermoregulated heating blanket. The animal head-holder, made of metal, was heated (by electrical heating elements) to skin temperature in order to prevent cooling of the cochlea. Tracheotomies were performed to ensure an adequate airway, and the subjects breathed spontaneously throughout the experiment. The right carotid artery was cannulated (polyurethane catheter tubing, Micro-Renathane, Braintree Scientific) to monitor systemic blood pressure (BP)and the right external jugular vein was cannulated for intravenous administration of drugs. The left bulla was exposed by a ventrolateral surgical approach and was carefully opened, preserving the function of the tympanic membrane and ossicles in all preparations. Using a cotton pledget, the mucosa and periosteum overlying the otic capsule were removed.

\section{$C B F$-recording}

A laser Doppler flowmeter (LDF) (Laser Flow, TSI Blood Perfusion Monitor 403) was used to monitor CBF. The LD probe was placed over the first or second cochlear turn. Petroleum gel was applied to the probe tip to provide efficient laser light coupling to the cochlea. All recordings were done under stable light illumination from the surgical microscope. The ratio of the change in CBF to the change in BP was also computed. This ratio, the normalized cochlear blood flow (nCBF) reflects flow changes in the cochlear circulation independent of the BP. A second LDF (Med Pacific, LD5000) was used to monitor skin blood flow (SBF) in some cases of each group. This skin probe was attached by tape to a shaved area of the abdomen.

\section{Experimental protocols}

Six agents, with different mechanisms for dilating vessels, were selected for this study. The drug-induced effects on CBF were examined after topical applications to the RWM and after systemic administration. The topical approach was developed in a previous study (Ohlsén et al., 1991) which took advantage of the diffusability of low molecular weight (MW) drugs through the RWM (Tanaka and Motomura, 1981; Ryback et al., 1984; Lundman et al., 1987; Morizono et al., 1989). The drugs selected for the current study had molecular weights below 500. Each of the six different drugs were also tested by IV administration. Regardless of route of application, the experiment began by recording stable $\mathrm{BP}$ and $\mathrm{CBF}$ baselines for at least 15 minutes before the test drug was administered.
For topical application experiments, two concentrations of each drug were studied. The topical administration consisted of a visually controlled application of 1-2 $\mu$ l of the tested drug to the RWM where the drug was allowed to remain for up to 2 hours. The vehicle (physiological saline) was tested independently by $2 \mu \mathrm{l}$ volume applications to the RWM. For systemic application experiments, IV administrations of two drug concentrations were measured and each was repeated when there was a fast and complete recovery from the drug effect; otherwise only a single drug application was tested for a given preparation. The systemic administrations were bolus injections $(0.3-0.5 \mathrm{ml})$ given via the venous catheter. The $\mathrm{CBF}$ was measured for up to 2 hours following drug administrations. If a recovery occurred following the drug-induced change in CBF, a control administration of the vehicle alone (0.3-0.5 ml) was given before the next drug concentration. The animals were sacrificed by an IV overdose of Uthol. The drugs, their MW, concentrations and most widely accepted mode of action are given in Table $I$.

All the animals tolerated the anesthesia and surgery well. Only animals with initial BP's above $40 \mathrm{mmHg}$ were used in this study.

\section{Results}

Control administration of the drug vehicles resulted in no significant change of CBF, BP, or SBF. This was the case regardless of whether they were administered topically or systemically. Moreover no change in BP or SBF was observed following the topical applications of the drugs to the RWM, even when the agent caused significant changes in $\mathrm{CBF}$.

\section{Topical administrations $(N=51)$}

The overall results of the current work are summarized in Table II. One can see in column 2 of Table II that three of the tested agents caused a noticeable increase in CBF when administered topically. They were sodium nitroprusside, hydralazine, and histamine. Sodium nitroprusside clearly induced the greatest effect. For the larger dose (3\% solution) CBF more than doubled. Figure $1 \mathrm{~A}$ shows the initial time course of change in CBF induced by the two concentrations of sodium nitroprusside from representative guinea pigs. Within 10 minutes following application of the drug, the laser Doppler flowmeter registered a maximum flux value. The larger CBF change (more than 100\%) was induced by the higher sodium nitroprusside concentration. There was no obvious recovery from these topically induced changes during the entire duration of the experiment ( 2 hours, although only 30 minutes is plotted in Fig. 1A). 
TABLE I

SUMMARY OF APPLIED DRUG CONCENTRATIONS, MOLECULAR WEIGHTS AND MODE OF ACTION

\begin{tabular}{|c|c|c|c|c|c|c|}
\hline & $\begin{array}{l}\text { Sodium } \\
\text { nitroprusside }\end{array}$ & Hydralazine & Histamine & Nicotinic acid & Papaverine & Verapamil \\
\hline $\begin{array}{l}\text { Concentrations } \\
\text { topical \% }\end{array}$ & 1,3 & 2,4 & 1,4 & 4,10 & 3 & 0,25 \\
\hline $\begin{array}{l}\text { Concentrations } \\
\text { I.V. } \mathrm{mg} / \mathbf{K g}\end{array}$ & $\begin{array}{l}0.0125 \cdot 10^{-3} \\
0.5 \cdot 10^{-3}\end{array}$ & $0.25,2$ & 0.005 & 5,10 & $0.1,0.5,1$ & 0.1 \\
\hline $\begin{array}{l}\text { Molecular } \\
\text { weight }\end{array}$ & 261.9 & 196.64 & 184.1 & 123.1 & 378.8 & 491.1 \\
\hline Mode of action & $\begin{array}{l}\text { guanylatecyclase } \\
\text {-cGMP }\end{array}$ & $\begin{array}{l}\text { guanylatecyclase } \\
\text {-cGMP }\end{array}$ & $\begin{array}{l}\text { receptors/second } \\
\text { messengers }\end{array}$ & $\begin{array}{l}\text { prostaglandins } \\
\text {-cAMP } \\
\text {-cGMP? }\end{array}$ & $\begin{array}{l}\text { phosphodiesterase } \\
\text { inhibitors-cGMP } \\
\text {-cAMP }\end{array}$ & $\begin{array}{l}\mathrm{Ca}^{2+}- \\
\text { channel } \\
\text { blocker }\end{array}$ \\
\hline
\end{tabular}

The CBF changes caused by topically applied hydralazine were generally similar to those of sodium nitroprusside (Fig. 1B). However the maximum increase was significantly less (by approximately 50\%) and some recovery following the peak change was apparent. The recovery occurred only during the first 30 minutes following peak action and the level of recovery was small. CBF remained elevated by at least half of its induced maximum change. The onset timecourse of CBF change was similar for the two drugs.

As indicated in Table II, topical histamine demonstrated variable and weak effects on CBF. Two of the 4 animals (in the high dose group) exhibited no CBF change following topically applied histamine, even when the application of the drug was repeated up to 4 times over a 1 hour period by removal and replacement of the 1-2 ml fluid volume on the RWM. The two animals that did show a change produced a steady rise in CBF over 30 minutes and no subsequent recovery during the next 1.5 hours.

No change in $\mathrm{CBF}$ was observed following topic administration of nicotinic acid, papaverine, or verapamil even with multiple applications to the round window rembrane.

\section{Intravenous applications $(N=39)$}

The one clear result indicated in Table II for the systemic administration of these vasodilators is the powerful influence they all have on BP (Table II). With the exception of the lower dose of nicotinic acid, BP

TABLE II

SUMMARY OF DRUG EFFECTS ON COCHLEAR BLOOD FLOW AND SYSTEMIC BLOOD PRESSURE

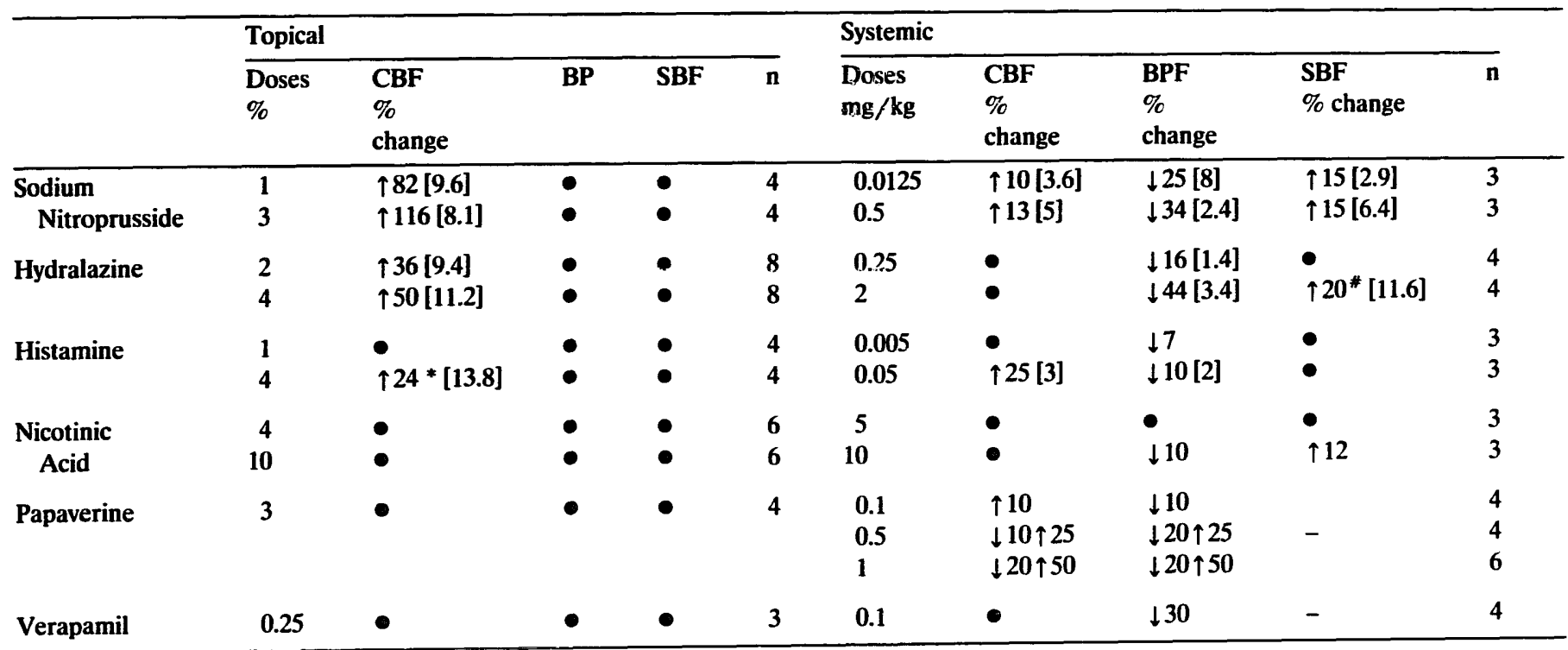

, no effect; -, not tested; *, 2 out of the 4 animals showed the effect: \#, 3 out of the 4 animals showed the effect. Columns giving \% change: mean [one standard deviation].

$\uparrow$ Increase; $\downarrow$ Decrease. 

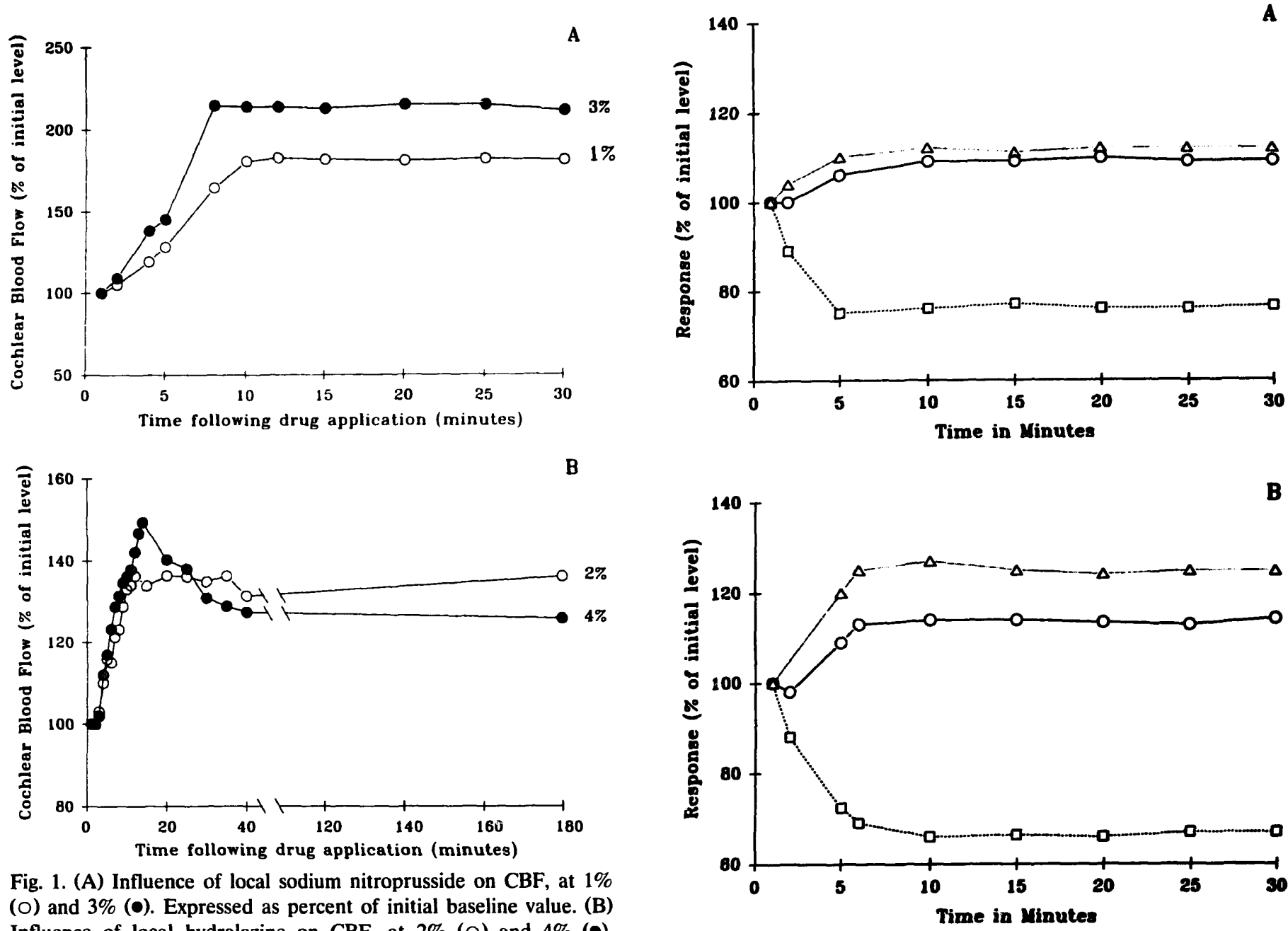

Fig. 1. (A) Influence of local sodium nitroprusside on $\mathrm{CBF}$, at $1 \%$ $(O)$ and 3\% (๑). Expressed as percent of initial baseline value. (B) Influence of local hydralazine on CBF, at $2 \%(O)$ and $4 \%(\bullet)$. Expressed as percent of initial baseline value.

reductions ranging to $44 \%$ were seen; and typically they were greater than $25 \%$. These substantial reductions were often accompanied by LD measured increases in blood flow in the skin and cochlea. Moreover it is noteworthy that in some instances CBF and SBF showed no change even though systemic blood pressure was reduced.

Figure 2 shows the BP, SBF and CBF changes induced by two concentrations of sodium nitroprusside given as bolus IV injections. This drug seems particularly interesting because its powerful vasodilative effect resulted in increase of both skin and cochlear blood flow even with large reductions in blood pressure. The alterations in BP and organ blood flow following IV administration generally showed partial or full recovery over 1 hour, while topical effects did not show recovery. However, there was no change in BP following topical administration.

The effect of systemically administered histamine was similar to that observed following topical applications of the drug, in that a slow change in CBF was induced over 30 minutes and only in some guinea pigs ( 2 out of 3 animals for the $10 \mathrm{mg} / \mathrm{kg}$ dose).

Fig. 2. Effects of intravenous administered sodium nitroprusside at $0.0125 \mu \mathrm{g} / \mathrm{kg}(\mathrm{A})$ and $0.5 \mu \mathrm{g} / \mathrm{kg}(\mathrm{B})$, on CBF $(O), \operatorname{SBF}(\Delta)$ and BP (). Expressed as percent of initial value.

Papaverine was unique among the tested agents in demonstrating short term and recoverable effects. Figure $3 \mathrm{~A}$ shows an example of the changes in $\mathrm{CBF}$ and $\mathrm{BP}$ observed following bolus IV injection in one guinea pig. These results are typical in that papaverine consistently showed a faster effect on CBF than on BP. Thus, if the CBF is normalized for the change in BP, a distinct residual response is seen for all doses tested (Fig. 3B). For the higher dose, a highly significant transient change in vascular conductivity of the cochlea occurs.

It is worthy of note that no decrease in CBF occurred for any of the agents even though reductions in BP were evident for all drugs.

\section{Discussion}

Each of the urugs examined in this investigation is well known for its cardiovascular action in different organs of the body (Goodman and Gilman, 1985). For 

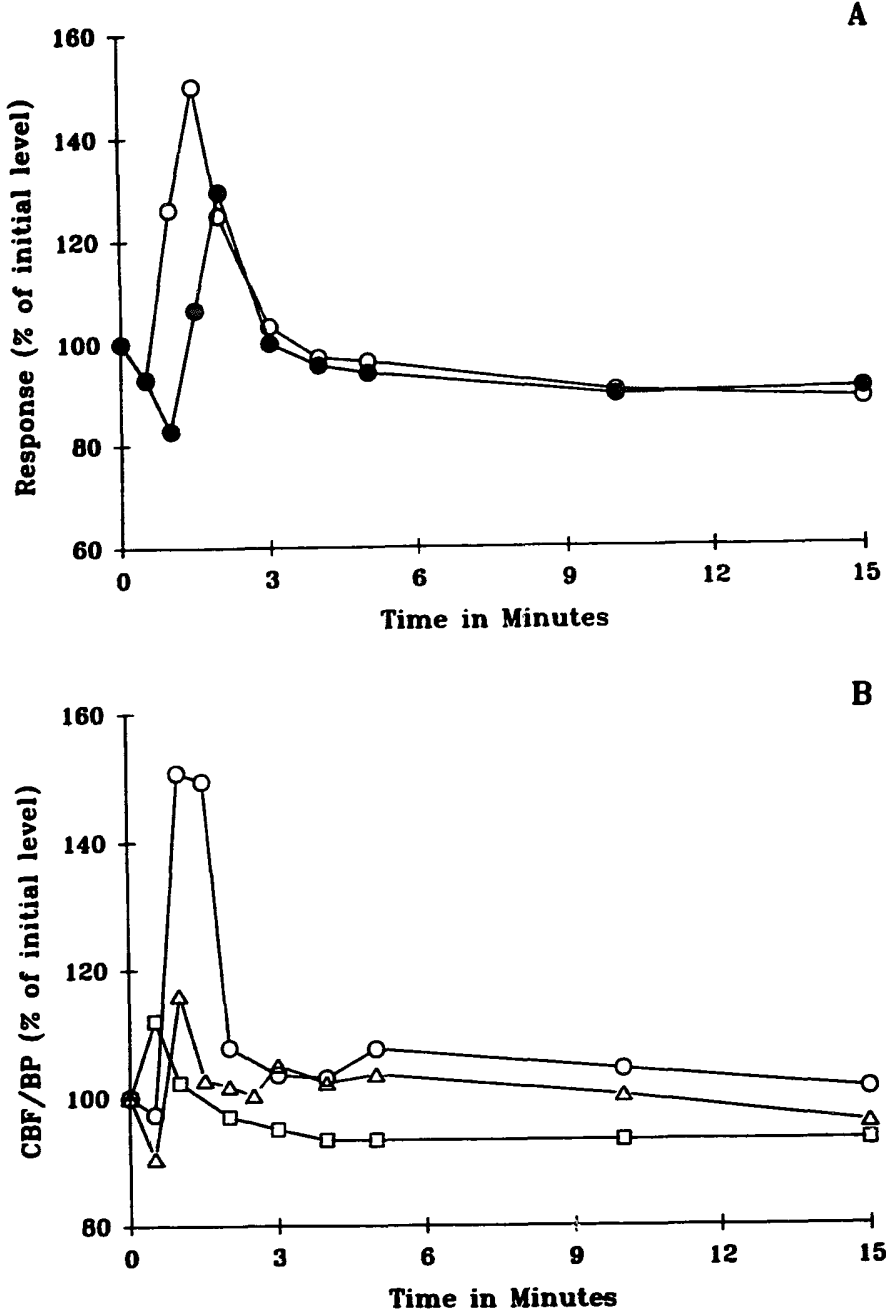

Fig. 3. (A) Influence of intravenous injection of $1.0 \mathrm{mg} / \mathrm{kg}$ papaverine on CBF $(\bullet)$ and on BP $(O)$. Expressed as percentage change from initial baseline. (B) Change in ration of CBF to BP with different doses of intravenous injections of papaverine. $1 \mathrm{mg} / \mathrm{mg}(O), 0.5$ $\mathrm{mg} / \mathrm{mg}(\Delta), 0.1 \mathrm{mg} / \mu \mathrm{g}(\square)$

the most part, they are anti-hypertensive agents or are in use for the treatment of angina pectoris. The influence of these agents on CBF, observed in this investigation, provides some indication of various pharmacological mechanisms available to the inner ear for controlling CBF. The fundamental mechanisms underlying drug induced vascular smooth muscle relaxation is unknown in many tissues. However, various generic mechanisms have been described and intensively studied. Basically, the drugs examined in this investigation have two principal modes of action both finally leading to dephosphorylation of myosin and inducing vascular relaxation (Greenberg et al., 1983; Gondman and Gilman, 1985; Waldman and Murad, 1987). A vasodilator may diroctly antagonize intracellular mechanisms responsible for the accumulation of free cytosolic calcium and/or it may initiate cascade reactions via cAMP and/or cGMP pathways. The drug can aiso block extracellular influx of calcium or activate different sec- ond messenger pathways via receptor binding that in turn block influx. Table I summarizes, in the bottom row, the perceived mode of action of the vasodilating agents used.

(1) Sodium nitroprusside and hydralazine stimulate the activity of guanylate cyclase, via the mediator nitrous oxide, resulting in elevation of intracellular cGMP. cGMP in the presence of $\mathrm{Ca}^{2+}$ leads to a dephosphorylation of myosin.

(2) The vasodilating action of histamine is complex. In part it may activate $\mathrm{H} 1$ and $\mathrm{H} 2$ receptors on vascular smooth muscle and on the endothelium. Activation of the receptors initiates a complex secondary pathway involving cGMP, cAMP and the prostaglandins resulting in myosin dephosphorylation. Inhibition of norepinephrine release has also been proposed as a possible mechanism for the vasodilatory action of histamine, as well as changes in vascular permeability (Greenberg et al., 1983; Woodward and Ledgard, 1986) and elevated levels of cGMP have also been associated with the action of histamine (Greenberg et al., 1983; Goodman and Gilman, 1985).

(3) Nicotinic acid induces vasodilation by elevating endothelial prostaglandins, which activate adenylate cyclase and possibly also guanylate cyclase (Goodman and Gilman, 1985) again leading to p-myosin dephosphorylation.

(4) Papaverine induces a rise in cAMP and/or cGMP via inhibition of phosphodiesterases, which are responsible for the breakdown of the cyclic nucleotides (Greenberg et al., 1983).

(5) Verapamil is a calcium channel antagonist, blocking the movement of extracellular calcium into smooth muscle cells, thereby restricting myofibril contractions which require the binding of calcium to contractable proteins. (Greenberg et al., 1983; Goodman and Gilman, 1985).

The RWM acts as a physical barrier to the inner ear. There is, however, evidence that active transport mechanisms exist within the membrane for the passage of large molecular weight proteins (Tanaka and Motomura, 1981; Lundman and Holmquist, 1987). Passive diffusion of smaller molecules up to $\mathrm{MW} 500$ has also been demonstrated (Ito, 1991). The drugs chosen for this study had a MW between 123 and 491 . However it is of interest that the two agents without effect after topical application, verapamil and papaverine, had higher MWs than the more effective drugs (Table I), indicating that their diffusion across the RWM may have been impeded. To evaluate this, some experiments with papaverine were conducted where the RWM was punctured to allow free mixing of drug with 
perilymph. In these experiments no effect on $\mathrm{CBF}$ was recorded.

In this study topically applied sodium nitroprusside and hydralazine were the most powerful vasodilating agents tested. They induced a dose-dependent response with no change in BP or SBF (Table II). These agents affect vascular smooth muscle by activation of the enzyme guanylate-cyclase. Nitroprusside and hydralazine release nitric oxide (NO) which has recently been identified as an endothelium-derived relaxing factor (Ignarro, 1989). NO is a very potent dilator, stimulating the production of cGMP via guanylate cyclase (Ignarro, 1989) (Table I). Sodium nitroprusside, which causes a larger effect on CBF than hydralazine, acts on the smooth muscle of both arterioles and venules, while hydralazine is a pure arteriolar dilator (Coodman and Gilman, 1985; Shepherd and Irvine, 1986). The findings of this study are consistent with the relative effectiveness of these agents described in other investigations (Nelson and Suresh, 1988). Sodium nitroprusside was the only drug which significantly increased CBF when administered intravenously. This effect was an approximately $10 \%$ increase in CBF; an effect of some significance given the $35 \%$ decrease in systemic BP.

The data are also partly consistent with the results reported for hydralazine by Snow and Suga (1973). In that study, systemically applied hydralazine increased cochlear blood flow (measured by impedance phlethysmography) and simultaneously decreased systemic blood pressure. Thus the normalized cochlear blood flow increased, as it did in the current work. The difference between the two studies regarding the absolute CBF for systemically administered hydralazine could be related to measurement methodology. Prazma et al. (1981) point out the potential shortcomings of impedance phlethysmography. Laser Doppler flowmetry, of course, is subject to different questions of interpretation (Nuttall, 1988).

Both topical and IV histamine caused an increase in CBF. When administered IV this was accompanied by a decrease in BP. The topical effect of histamine on CBF was not a consistent finding, being observed in only half of the animal tests. However, the positive result may be interpreted as evidence supporting local histamine receptors in the vasculature of the guinea pig cochlea. Given current knowledge of histamine receptors and the physiology of their action in different organs (Goodman and Gilman, 1985), it is impossible to state whether the effect seen in the cochlea was mediated via a $\mathrm{H} 2$ or both $\mathrm{H} 1$ and $\mathrm{H} 2$ receptor/s.

Nicotinic acid did not affect CBF. This is consistent with observations made on brain blood flow and in previous study on CBF. Hultcrantz et al.(1982) found no effect on CBF when nicotinic acid was administered IV in intact animals. However, when nicotinic acid was given to animals during electrical stimulation of the cervical sympathetic chain, an increase of the reduced CBF by $25 \%$ was registered. In the present study nicotinic acid increased only SBF. The vasodilation in the skin may be mediated through release of prostaglandins (PG) as it is inhibited by aspirin (Goodman and Gilman, 1985). Since PGs are synthesized in the inner ear (Escoubet et al., 1985), the lack of effect of nicotinic acid on CBF suggests that something more is necessary to activate the vasodilative mechanism. Further experiments including sympathetic stimulation would help to clarify this question.

Topically applied papaverine was ineffective in increasing the CBF, but when given IV in the highest dose tested, it was found to increase CBF more than it changed the BP. The increased nCBF suggests a transient additional local dilating effect of papaverine on the cochlear vasculature. These transient increases in CBF appear consistent with the findings of Snow and Suga (1973) and Prazma et al. (1988) for papvarin and ethaverin, respectively, who show increased CBF and decreased systemic blood pressure during systemic administrations.

Topical application of verapamil failed to induce changes in CBF or BP. However, following IV administration a marked decline in BP was observed with the CBF falling less. This may indicate a small effect of verapamil on cochlear vasculature smooth muscle but in the absence of a topical effect it may also be interpreted as evidence to support local autoregulation.

From a clinical viewpoint, a significant finding of this study was that systemic administration of potent vasodilating agents resulted in little or no net increase in the CBF. Moreover, the resultant hypotensive effects in the guinea pig model put into question their use in the treatment of suspected inner ear ischemia. The cochlear blood circulation is anatomically closely related to the much larger intracerebral circulation. By implication it may be subject to autoregulatory mechanisms to provide constant blood flow over a wide range of perfusion pressures. A distinct autoregulatory system within the cochlea could act separately (Hultcrantz et al., 1977; Miller and Dengerink, 1988) from the cerebral circulation. On the other hand, local administration of vasodilator drugs to the cochlear microcirculation via the RWM can result in selective improvements of CBF with no effect on BP. The marked elevations of CBF following administration of nitroprusside and hydralazine is evidence of this. The duration of this blood flow response is prolonged, in the case of nitroprusside, over 2 hours. This is in contrast to the known transient action of nitroprusside when administered systemically in man (Goodman and Gilman, 1985). The reason for this prolonged effect is not known at this time, but could be related to the 
effective dose reaching the smooth muscle of cochlear vessels or to slow clearance of the drug from cochlear fluids.

We believe that the model developed for this study, i.e., the local application of drugs directly to the cochlea, is a valid and useful one to assess their cochlear vascular activity. As usual, caution must be exercised in the interpretation of these results, for unanesthetized animals not subjected to surgical trauma. Furthermore, there is the important question of whether increased blood flow is of any benefit for the cochlear function. Further studies assessing stability or changes in cochlear physiology associated with these drugs, are required to provide an adequate rationale to support this strategy of treatment for clinical use in man.

\section{Acknowledgements}

This work was supported by NIH NIDCD individual grant DC-00105. The authors thank J.N. Brown and C.H. Hall for technical assistance in data analysis.

\section{References}

Axelsson, A. (1971) The cochlear blood vessels in guinea pigs of different ages. Acta Otolaryngol. 72, 172-181.

Brown, M.C., Nuttall A.L., Masta, R.I. and Lawrence, M. (1983) Cochlear inner hair cells: Effects of transient asphyxia on intracellular potentials. Hear. Res. 9, 131-144.

Cummingham, D.R. and Goetzinger, C.P. (1974) Extra high frequency hearing loss and hyperlipidemia. Audiology 13, 470-484.

Escoubet, B., Amsallem, P., Ferrary, E. and Tran Ba Huy. P. (1985) Prostaglandin synthesis by the cochlea of the guinea pig. Influence of aspirin, gentamicin, and acoustic sitmulation. Prostaglandins 29, 589-599.

Goodman, L. and Gilman, A. (1985) The Pharmacological Basis of Therapeutics, 7th Edn., MacMillan Publishing Co., New York.

Greenberg, S., Curro, F.A. and Tanaka, T.P. (1983) Regulation of vascular smooth muscle of the microcirculation. In: N.A. Mortillaro (Ed.), The Physiology and Pharmacology of the Microcirculation, Vol. 1, Harcourt Brace Jovanovich, New York.

Hultcrantz, E., Linder, J. and Angelborg, C. (1977) Sympathetic effects on cochlear blood flow at different blood pressure levels. Inserm 68, 271-278.

Hultcrantz, E., Hillerdal, M. and Angelborg, C. (1982) Effect of nicotinic acid on cochlear blood flow. Arch. Otorhinolaryngol. 234, 151-155.

Hultcrantz, E. (1988) Clinical treatment of vascular inner ear diseases. Am. J. Otolaryngol. 9, 317-322.

Ignarro, L.J. (1989) Endothelium derived nitric oxide: Actions and properties. FASEB Journal 3, 31-36.

Ito, Z., Salt, A.N. and Thalmann, R. (1991) Solute movements across the round window membrane. Abstracts of 14th midwinter meeting of Association for Research in Otolaryngology: 108.

Johnson, A., Hawke, M. and Berger, G. (1984) Sudden deafness and vertigo due to inner ear hemorrhage: a temporal bone case report. 13, 201-207.

Johnsson, L.-G. and Hawkins, J.E. (1972) Vascular changes in the human inne: car associated with aging. Ann. Otol. Rhinol. Laryngol. 81, 364-376.
Lawrence, M., Nuttall, A.L. and Burgio, A.B. (1975) Cochlear potentials in oxygen associated with hypoxia. Ann. Otol. Rhinol. Laryngol. 84, 499-512.

Lundman, L., Holmquist, L. and Bagger-Sjoback, D. (1987) Round window membrane permeability: An in vitro model. Acta Otolaryngol. Suppł. (Stockholm) 104, 472- 480.

Mattox, D.E. (1980) Medical management of sudden hearing loss. Acta Otolaryngol. 80, 111-113.

Miller, J. and Dengerink, H. (1988) Control of inner ear blood flow. Am. J. Otol. 9, 302-316.

Miller, J.M., Marks, N.J. and Goodwin, P.C. (1983) Laser Doppler measurements of cochlear blood flow. Hear. Res. 11, 385-394.

Miller, J.M., Goodwin, P.C. and Marks, N.J. (1984) Inner ear blood flow measured with a laser Doppler system. Arch. Otolaryngol. $110,305-308$.

Morizono, T., Smith, R., Chap, T., Canafax, D. and Diebink, S. (1989) Ototoxicity of topically applied drugs used in otitis media treatment. In: D.J. Lim, C.D. Bluestone, J.O. Klein and J.D. Nelson (Eds.), Recent Advances in Otitis Media. B.C. Decker, Inc., Philadelphia, Proceedings of the 4th International Symposium.

Nakatsu, K. and Diamond, J. (1989) Role of cGMP in relaxation of vascular and other smooth muscle. Can. J. Physiol. Pharmacol. 67, 251-262.

Nelson, S.H. and Suresh, M.S. (1988) Comparison of nitroprusside and hydralazine in isolated uterine arteries from pregnant and non-pregnant patients. Anesthesiology 68, 541-547.

Nuttall, A.L. (1988) Cochlear blood flow: Measurement techniques. Am. J. Otolaryngol. 9, 291-301.

Ohlsén, K.A., Baldwin, D.L., Nuttall, A.L. and Miller, J.M. (1991) Influence of topically applied adrenergic agents on cochlear blood flow. Circulation Res. 69, 509-518.

Prazma. J. (1981) Effect of glycerol on cochlea microcirculation. Acta Otolaryngol. 92, 459-461.

Prazma, J., Biggers, W.P. and Fischer, N.D. (1981) Effect of ethaverine hydrochloride on cochlear microcirculation. Arch. Otolaryngol. 107, 227-229.

Rybak, L.P., Wright, L.B. and Whitworth, C. (1984) Cochlear effects of locally applied inhibitors. Arch. Otorhinolaryngol. 240, 207213.

Shepherd, A.M. and Irvine, N.A. (1986) Differential hemodynamic and sympathoadrenal effects of sodium nitroprusside and hydralazine in hypertensive subjects. J. Cardiovasc. Pharmacol. 8, $527-533$

Sillman, J.S., LaRouere, M.J., Nuttall, A.L., Lawrence, M. and Miller, J.M. (1988) Recent advances in cochlear blood flow measurements. Ann. Otol. Rhinol. Laryngol. 97, 1-8.

Snow, J.B. and Suga F. (1973) Labyrinthine vasodilators. Arch. Otolaryngol. 97, 365-370.

Tami, T.A., Frankhauser, C.E. and Mehlum, D.L. (1985) Effect on noise exposure and hypercholesterlemia on the auditory function in the New Zealand white rabbit. Otolaryngol. Head Neck Strrg. 93, 235-238.

Tanaka, K. and Motomura, S. (1981) Permeability of the labyrinthine windows in guinea pigs. Arch. Otorhinolaryngol. 233, 67-75.

Thorne, P.R. and Nuttall, A.L. (1987) Laser Doppler measurements of cochlear blood flow loud sound exposure in the guinea pig Hear. Res. 27, 1-10.

Waldman, S.A. and Murad, F. (1987) Cyclic GMP synthesis and function. Pharmacol. Rev. 39: 163-196.

Woodward, D.F. and Ledgard, S.E. (1986) Histamine-induced microvascular permeability increases in hamster skin: a response predominantly mediated by $\mathrm{H} 2$ - receptors. Agents Actions 18 , 504-507.

Zajtchuk, J.T., Falor, W.T. and Rhodes, W.F. (1979) Hypercoagulability as a cause of sudden sensorineural hearing loss. Otolaryngol. Head Neck Surg. 87, 268-273. 